University of Nebraska - Lincoln

DigitalCommons@University of Nebraska - Lincoln

$4-3-1980$

\title{
Relationship Between Relative Brain Size and Climbing Ability in Peromyscus
}

Cliff A. Lemen

University of Nebraska-Lincoln, clemen2@unl.edu

Follow this and additional works at: https://digitalcommons.unl.edu/natrespapers

Part of the Natural Resources and Conservation Commons, and the Zoology Commons

Lemen, Cliff A., "Relationship Between Relative Brain Size and Climbing Ability in Peromyscus" (1980). Papers in Natural Resources. 34.

https://digitalcommons.unl.edu/natrespapers/34

This Article is brought to you for free and open access by the Natural Resources, School of at DigitalCommons@University of Nebraska - Lincoln. It has been accepted for inclusion in Papers in Natural Resources by an authorized administrator of DigitalCommons@University of Nebraska - Lincoln. 
Norris, K. S. (ed.). 1961. Standardized methods for measuring and recording data on the smaller cetaceans. J. Mamm., 42:471-476.

TARUSKi, A. G., C. E. OlNey, and H. E. WINN. 1975. Chlorinated hydrocarbons in cetaceans. J. Fish. Res. Bd. Canada, 32:22052209.
Thompson, N. P., P. W. Rankin, AND D. W. JOHNSTON. 1974. Polychlorinated biphenyls and p, p -DDE in green turtle eggs from Ascension Island, South Atlantic Ocean. Bull. Environ. Contam. Tox., 11:399-406.

White, J. R. 1976. A pygmy killer whale found on the east coast of Florida. Florida Sci., 39:31-36.

Donald J. Forrester, Daniel K. Odell, Neal P. Thompson, ANd Jesse R. White, Laboratory of Wildlife Disease Research, College of Veterinary Medicine, University of Florida, Gainesville, FL 32610; Division of Biology and Living Resources, Rosenstiel School of Marine and Atmospheric Science, University of Miami, 4600 Rickenbacker Causeway, Miami, FL 33149; Pesticide Research Laboratory, Food Science and Human Nutrition Department, University of Florida, Gainesville, FL 32611; and Wometco Miami Seaquarium, 440 Rickenbacker Causeway, Miami, FL 33149. Submitted 30 January 1979. Accepted 4 September 1979.

J. Mamm., 61(2):356-360, 1980

\section{RELATIONSHIP BETWEEN RELATIVE BRAIN SIZE AND CLIMBING ABILITY IN PEROMYSCUS}

Eisenberg and Wilson (Evolution, 32:740-751, 1978) have documented an interesting relationship between the relative brain size of bats and the complexity of the habitat in which they forage. They found that bats that $\mathrm{fly}$ and forage through foliage have larger brains relative to their body size than those that forage in open air. Their explanation was that bats in the complex habitat must process more complex sonic information to navigate through the foliage. In order to do this a larger brain is required.

The Peromyscus of North America may offer a similar paradigm as far as habitat complexity is concerned. Species of this genus can be found associated with a variety of habitats: forest, brushlands, rock slides, and grasslands. It seems reasonable that these structurally different habitats may require different climbing abilities by the Peromyscus inhabitants. If functioning in a structurally complex habitat requires a relatively larger brain to process information than is required in a structurally simple habitat, then, following the logic of Eisenberg and Wilson (1978), those species that are good climbers will have relatively larger brains than species that are poor climbers. If this hypothesis is correct, such a pattern of morphological variation in brain size may be expected intraspecifically in P. maniculatus and P. leucopus, two species that occur in a wide variety of habitats throughout their range.

Assessing the volume of the brain cavity is a simple process; however, determining the climbing ability of a rodent species is more difficult. Although Horner (Contr. Lab. Vert. Biol., Univ. Michigan, 635:1-85, 1954) performed series of tests to rank the climbing ability of some species of Peromyscus, too few have been done to perform the analyses I present here. However, Horner also found that tail length is associated with climbing ability in Peromyscus. For this reason I used relative tail length (tail length/head and body length) as an index of climbing ability.

All specimens used in this study are housed in the Field Museum of Natural History, Chicago. Individuals of a species or subspecies from the same locality were used to form series from which data were averaged. The taxa chosen (see Hall and Kelson, The mammals of North America, The Ronald Press Co., New York, 2:547-1083 + 79 pp., 1959) and the sample sizes used are: Peromyscus boylii, 3; P. californicus, 3; P. crinitus, 3 ; P. difficilis, 5 ; P. eremicus, 3 ; P. floridanus, 3; P. leucopus texanus, 3; P. l. affinis, 3; P. l. aridulus, 3; P. l. arizonae, 3; P. l. leucopus, 3; P. l. mesomelas, 3; P. l. noveboracensis, 5; P. l. tornillo, 4; P. maniculatus bairdii, 8; P. m. abietorum, 7; P. m. austerus, 8 ; P. m. blandus, 9; P. m. borealis, 5 ; P. m. fulvus, 10; P. m. gambelii, $9 ;$; . m. gracilis, 10; P. m. hylaeus, $5 ;$; . m. macrorhinus, $4 ;$; . m. maniculatus, $3 ; P$. m. nebrascensis, 7; P. m. nubiterrae, 5; P. m. osgoodi, 10; P. m. rubidus, 10; P. m. rufinus, 9; P. m. sonoriensis, 6; P. gossypinus, 3; P. pectoralis, 3; P. sitkensis, 3; and P. truei, 5. Label 


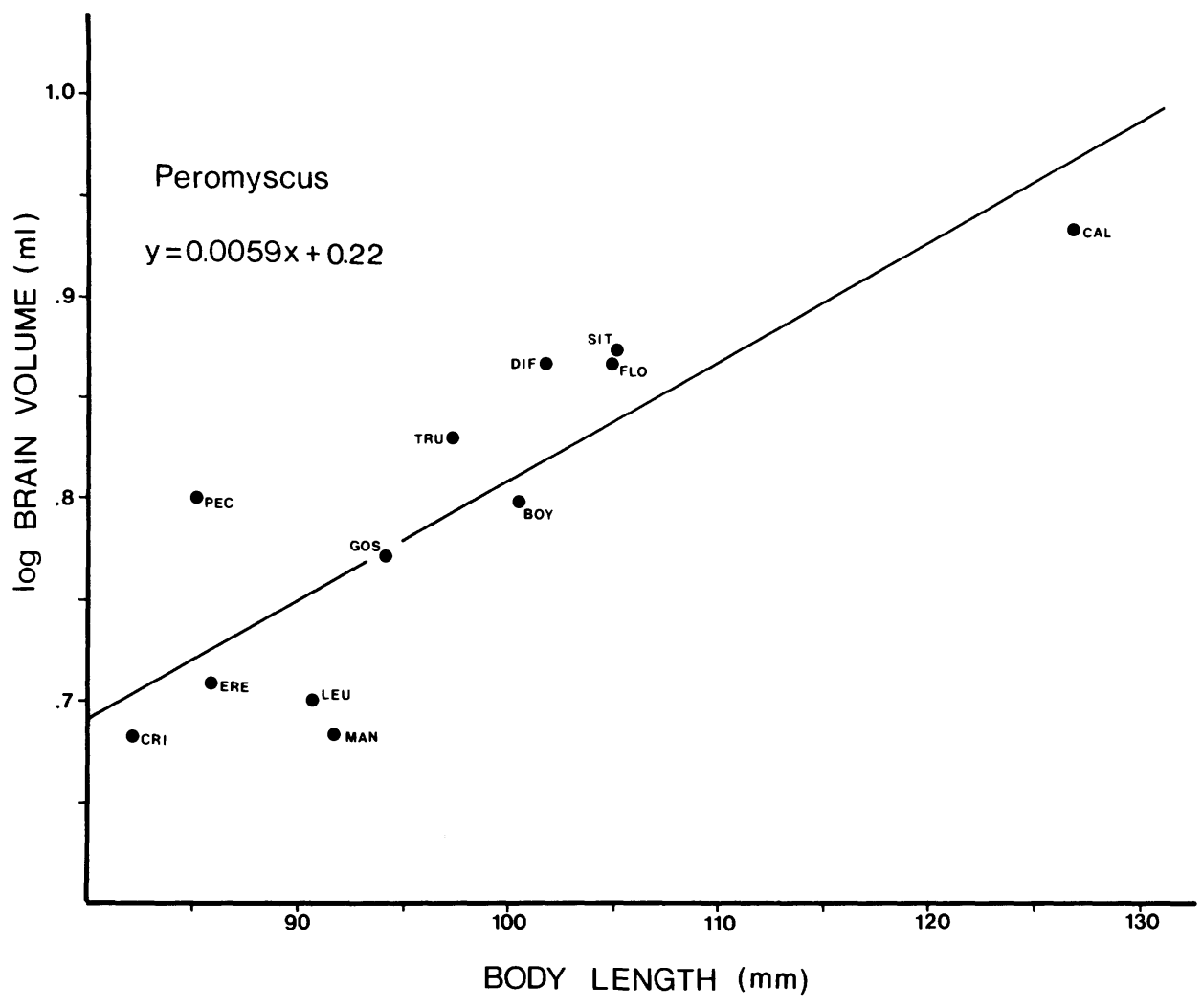

Fig. 1.-Scattergram of brain volume (log transformed) and body length for 12 species of Peromyscus. The points are identified with a sufficient number of the first letters of their trivial name to form an unique abbreviation. The regression line is also shown, $F$ value $=24.70, P<$ 0.001 .

information for total and tail length were recorded for each specimen. Following the methods of Findley (J. Mamm., 50:340-344, 1969) and Eisenberg and Wilson (1978), brain volumes were estimated using the weight of lead shot required to fill the brain cavity.

Clearly, there is a general relationship between body size and brain size in any group (Jerison, Evolution of the brain and intelligence, Academic Press, New York, 482 pp., 1973). Here, however, I was only interested in relative brain size; therefore, the effect of body size was removed from the brain-size data by use of a regression analysis. Fig. 1 is a scattergram of head and body length versus brain volume for 12 species of Peromyscus. A regression was performed between these two variables (after a logarithmic transformation, base 10, of the brain volume data) and as expected the relationship was positive and significant $(P<0.001$, one-tailed $F$ test). The regression line generated from this analysis is also shown in Fig. 1. About $42 \%$ of the total variation in brain volume can be explained by body size. This leaves $58 \%$ of the variation in brain size to be explained by all other factors. The deviations of each point from the regression line (Fig. 1) represent the unexplained variance; these deviations or residuals by their sign and magnitude indicate relative brain size. A positive residual (point above the regression line) signifies a relatively large brain for that body length and a negative residual (point below the regression line) signifies a relatively small brain volume for that body length. The model of Eisenberg and Wilson, that relative brain size will be correlated with habitat complexity, generates the prediction that there will be a positive relationship between these residuals and relative tail length, which is correlated with climbing ability and habitat complexity. The scattergram of the residuals from Fig. 1 and relative tail length for each species of Peromyscus are shown in Fig. 2. The 


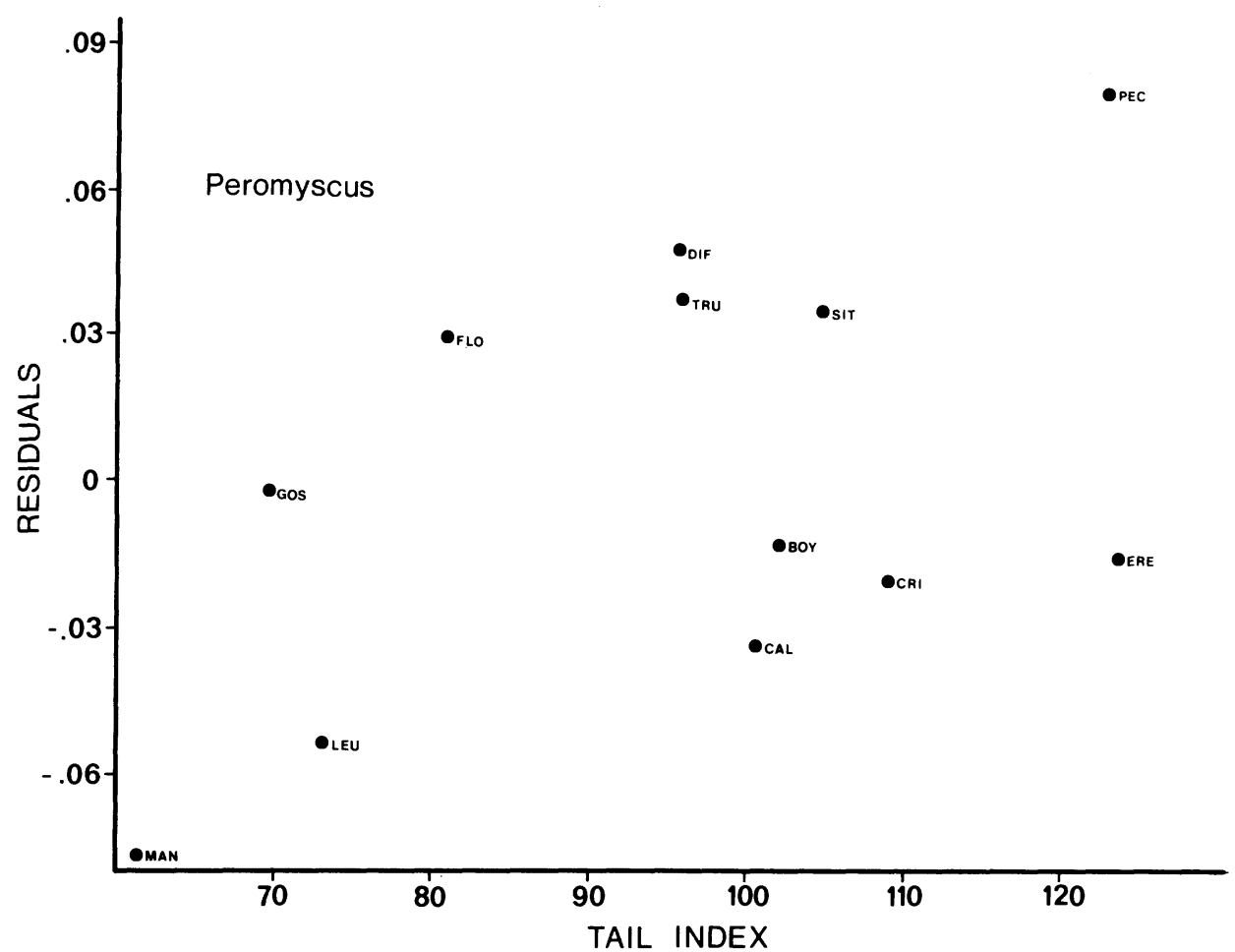

Fig. 2.-Scattergram of the residuals from the regression in Fig. 1 and the tail index for 11 species of Peromyscus (trivial names abbreviated). The correlation coefficient $(r)$ is $0.499, P<$ 0.05 .

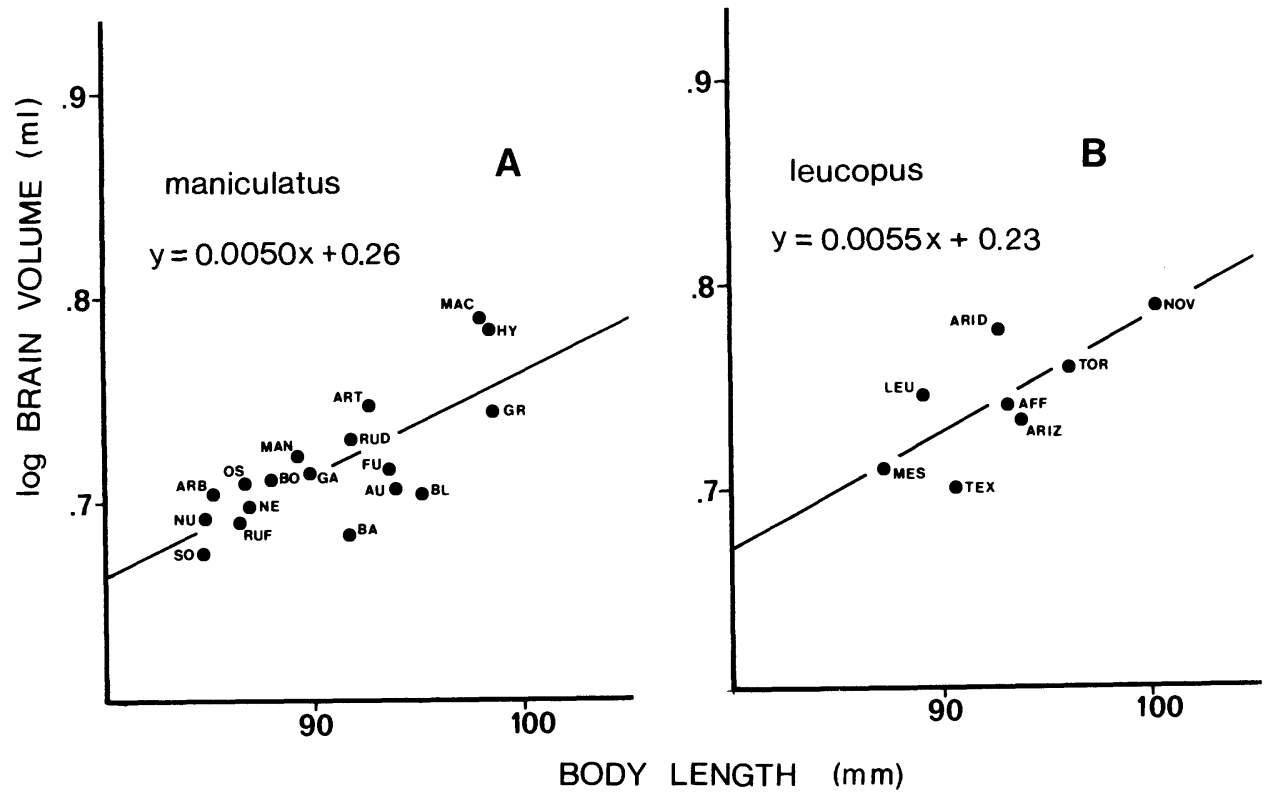

FIG. 3.-Scattergrams of the relationships between brain volume and body length for subspecies of $P$. maniculatus (A), and P. leucopus (B). The regression lines are also shown; A) $F$ value $=$ $20.62, P<0.0005$; B) $F$ value $=7.62, P<0.05$. 


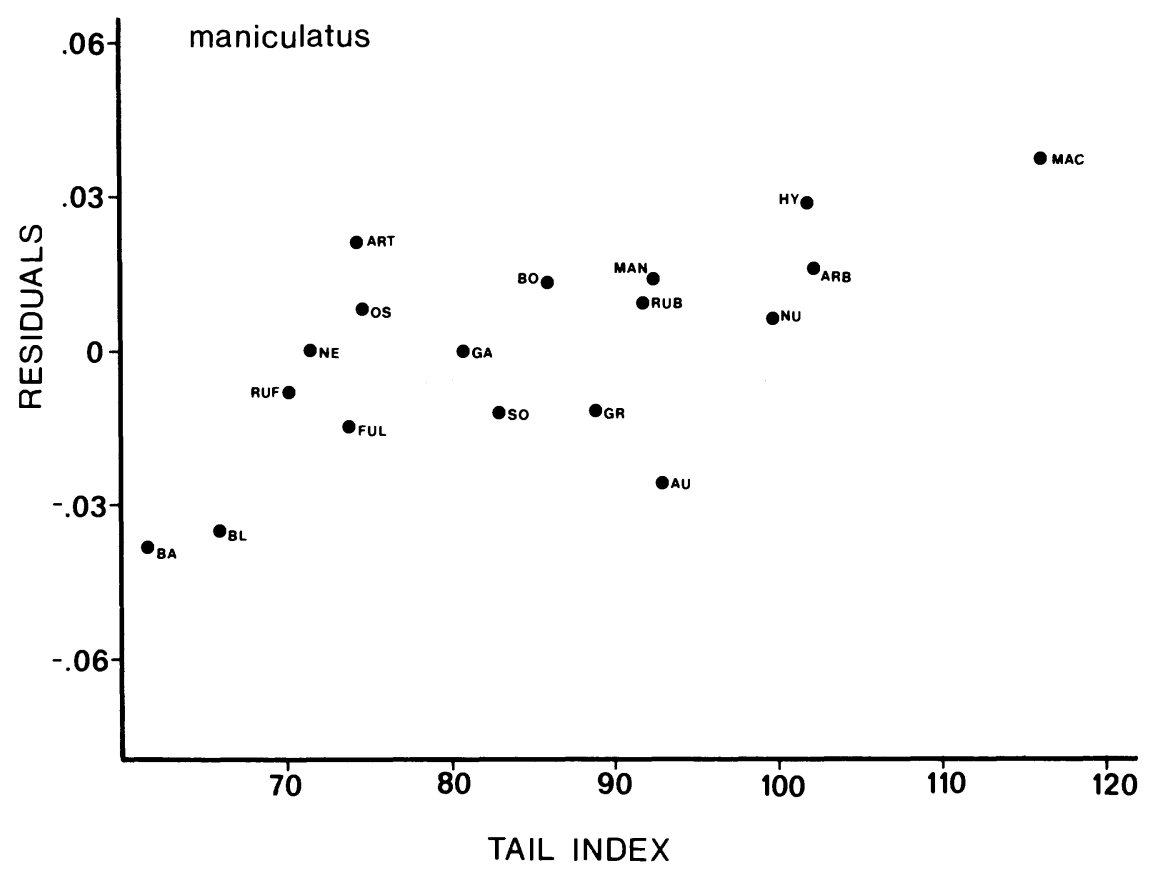

FIG. 4.-Scattergram of the residuals from the regression in Fig. $3 \mathrm{~A}$ and the tail index for 18 subspecies of $P$. maniculatus; the correlation coefficient $(r)$ is $0.666, P<0.0025$.

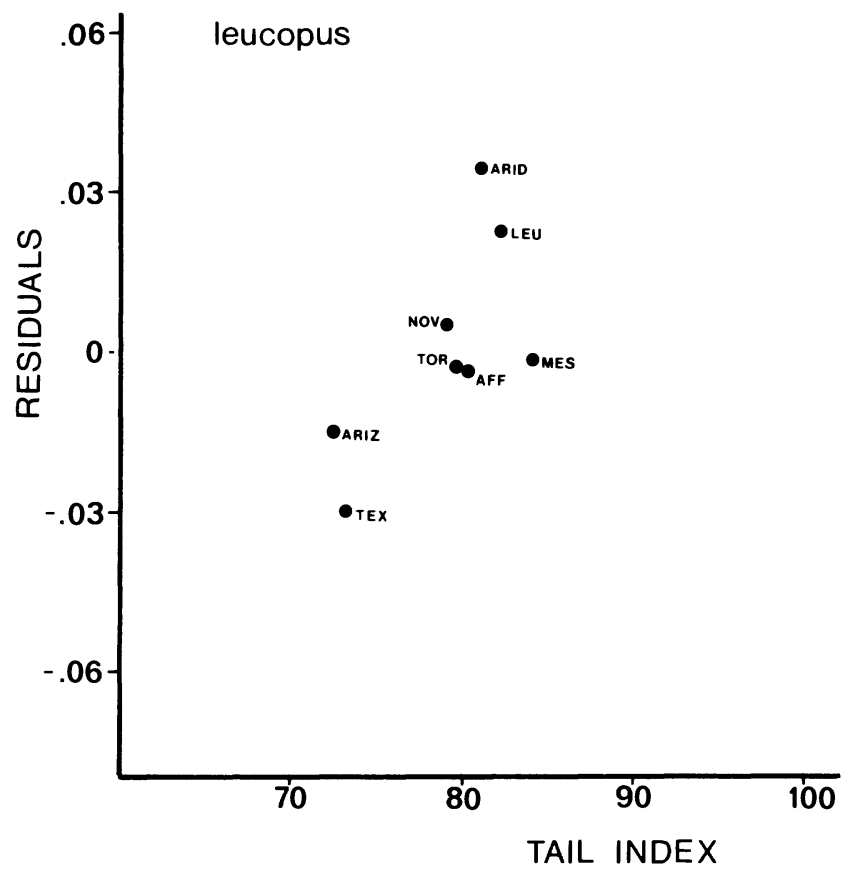

Fig. 5.-Scattergram of the residuals from the regression in Fig. 3B and the tail index for eight subspecies of $P$. leucopus; the correlation coefficient $(r)$ is $0.692, P<0.05$. 
correlation between these two variables is positive and significant $(r=0.50, P<0.05$, one-tailed test). The explained variance $\left(\mathrm{r}^{2}\right)$ is $25 \%$; nevertheless, as can be seen in Fig. 2 there is still considerable unexplained variance. One possible explanation is that the relationships among tail index, climbing ability, and relative brain size are not constant through these species of Peromyscus. In an attempt to reduce this source of variation, as well as further test the relationship, I performed a similar analysis on samples of subspecies of a single species.

Species used in the single-species analyses were Peromyscus maniculatus and P. leucopus. $P$. maniculatus is particularly suited to such a test. This species ranges across most of North America, occurs in a variety of habitats ranging from boreal forest to desert grassland, and exhibits considerable geographic variation. Much of this variation is due to the dichotomy between the morphology of individuals from forest versus grassland populations. The forest dwellers tend to have larger ears and longer tails than those that inhabit grasslands. Horner (1954) found that grassland-inhabiting subspecies are relatively poorer climbers than the forest subspecies. The analysis outlined above for species of Peromyscus was repeated for subspecies of P. maniculatus (Fig. 3). The correlation between the residuals from Fig. 3 and relative tail length is significant $(r=0.67 ; P<0.0025$; one-tailed test; Fig. 4). Limiting the analysis from many species to one species has increased the explained variance from 25 to $45 \%$.

Peromyscus leucopus is also widely distributed in North America; however, this species appears less differentiated morphologically, either by the criteria of fewer subspecies recognized by taxonomists (17 for leucopus versus 66 for maniculatus) or by variation in tail index (Fig. 3).

The scattergram of residuals to tail index for P. leucopus is shown in Fig. 5; the correlation is significant $(r=0.70 ; P<0.05$; one-tailed test). From comparing Figs. 4 and 5 , it is clear that while the tail index varies more in subspecies of $P$. maniculatus, the variation in relative brain size is similar. This yields a steeper relationship between tail index and relative brain size in $P$. leucopus.

The hypothesis proposed by Eisenberg and Wilson (1978), that navigating through structurally complex habitats requires relatively larger brains, is supported by both inter- and intraspecific data from Peromyscus.

ChIfF Lemen, Department of Zoology, Field Museum of Natural History, Roosevelt Road at Lake Shore Drive, Chicago, IL 60605. Submitted 12 May 1978. Accepted 5 November 1979.

J. Mamm., 61(2):360-364, 1980

\section{EUTAMIAS GROWTH RATES: ADDITIONAL CORRECTIONS}

Levenson (J. Mamm., 60:232-235, 1979) provided additional information and corrected growthrate constants for 20 species of sciurids after pointing out miscalculations published by Morton and Tung (J. Mamm., 52:611-616, 1971) and Hirshfeld and Bradley (J. Mamm., 58:44-52, 1977). The purpose of this note is to alert readers to additional errors in the publication by Hirshfeld and Bradley (1977) and the M.S. thesis from which it was derived (Hirshfeld, unpubl. M.S. thesis, Univ. Nevada, Las Vegas, 1975).

The values in figures 1 and 2 (Hirshfeld and Bradley, 1977) are not rate functions as presented. Multiplying them by 100 will not equal the percentage increase in weights or body measurements per week, let alone the percentage increase per day as stated in the figure legends. The percentage increase per week can be obtained from the antilogs of the numbers. In the paragraph Increase in Body Weight, Hirshfeld and Bradley $(1977$, p. 48) state that “. . in the first phase, weight increased $17.7 \%$ per week for the larger species, E. palmeri, and $9.7 \%$ per week for $E$. panamintinus." Data in their Table 1 suggest that the weight of E. palmeri increased $50.4 \%$ per week (weeks 1-3), whereas E. panamintinus gained weight by $24.4 \%$ per week (weeks 1-6). Had the data in Table 1 been multiplied by the alleged percentage values in figures 1 and 2, the error would not have occurred.

The rationale for splitting the data in figures 1 and 2 into arbitrary segments is not clear. There is no comparison with similar curves fitted to data for other species, and the values were not 